\title{
Characterization, biological activities, and authentication of red fruit (Pandanus conoideus Lam) oil
}

\author{
${ }^{1,2^{*}}$ Rohman, A. and ${ }^{1}$ Windarsih, A. \\ ${ }^{1}$ Department of Pharmaceutical Chemistry, Faculty of Pharmacy, Gadjah Mada University, Yogyakarta \\ 55281, Indonesia \\ ${ }^{2}$ Research Centre of Halal Products, Gadjah Mada University, Yogyakarta 55281, Indonesia
}

\begin{abstract}
Article history:
Received: 10 August 2017

Received in revised form: 2

September 2017

Accepted: 4 September 2017

Available Online: 2 October 2017
\end{abstract}

\section{Keywords:}

Red fruit oil,

Physico-chemical properties,

Biological activity,

Authentication

\section{DOI:}

https://doi.org/10.26656/fr.2017.2(2).152

\begin{abstract}
Red fruit (Pandanus conoideus Lam) oil (RFO) is one of high value edible oils having many functional advantages for health. $P$. conoideus is a native plant from Papua province, Republic of Indonesia and Papua New Guinea. RFO is good for diets and served as preventive agents for various diseases such as cancer and coronary disease so that RFO can be considered as functional edible oils. Because of its high quality, in Indonesia fats and oils market, RFO has a more expensive price (10-15 times) than other common edible oils like palm oil and corn oil. This fact attracts some unethical player to adulterate RFO with other lower priced-oils such as palm oil and corn oil. As a consequence, the authentication of RFO from any oil adulterants becomes important to ensure the quality and the authenticity of RFO. This article report some biological advantages of RFO and the characterization of RFO. FTIR spectroscopy in combination with multivariate calibrations has been reported as a powerful technique for the authentication of RFO from other oils and is the most reported techniques in some literature.
\end{abstract}

\section{Introduction}

Red fruit (Pandanus conoideus Lam) is a special and typical plant (endemic) which grow at Papua Island, i.e. Papua (Indonesia) and Papua New Guinea. The shape of the fruit is oval with bright maroon red color. The fruit has $55 \mathrm{~cm}-100 \mathrm{~cm}$ long, $10-15 \mathrm{~cm}$ diameter, and $2-3 \mathrm{~kg}$ weight (Bourke, 2005). RFO is known as functional oils, having relatively complete essential vitamins and minerals. RFO also contains high doses of beta-carotene, tocopherol, and essential fatty acids of oleic and linolenic acids (Budi and Paimin, 2004). The high quality of RFO not only served as a diet but also as preventive agents of various degenerative diseases. Nowadays, RFO is widely distributed over the world, also in other provinces of Indonesia. RFO is labeled as daily oil diet which is good for health. The price of RFO is approximately 10-15 times higher than other vegetable oils such as palm, soybean, and canola oil. RFO has been considered as functional oil having a beneficial effect on human health (Rohman and Che Man, 2011).

Because of its prices, the authentication of RFO becomes more important to verify and to ensure the originality of RFO. RFO is potential to be adulterated with other lower price oils such as palm oil, corn oil, sesame oil and others (Setyaningrum et al., 2013). Adulteration of high quality oils with lower oils is a serious problem not only for producers but also for consumers. The adulteration practice was related to health aspects, and in some cases, adulteration can be related to certain religion if adulterant is non-halal components for Muslim like lard (Rohman and Che Man, 2008). In order to assure the quality and the safety of RFO, the oil characteristics must be defined via determining several physico-chemical properties in order to assure the quality of RFO. This review aims to highlight some physico-chemical properties of RFO along with the biological activities and to describe FTIR spectroscopy combined with chemometrics for authentication of RFO from potential adulteration with low priced oils.

\section{Characterization of red fruit oil}

RFO is a vegetable oil obtained from the extraction process of red fruit. Due to the increasing numbers of RFO products in Indonesia fats and oils market, it is important to define the standard characteristics of RFO. Some quality parameters and requirements of RFO are proposed, including organoleptic (smell, taste, colour), 
microbial contamination, and other physico-chemical properties including acid value, iodine value, saponification value, conjugated diene and triene values, anisidine values, coefficient of absorptivity, volatile compounds, and fatty acid composition (Mousavi et al., 2012).

Arumsari et al. (2013) have compared physicochemical properties of RFO obtained using hexane and chloroform solvents, to obtain hexane fraction and chloroform fraction. Acid value represents the free fatty acids present in fats and oils. The lower the acid value, the better the fats and oils. RFO in hexane fractions has the lower acid value $(100.63 \pm 3.36 \mathrm{mg} \mathrm{KOH} / \mathrm{g} \mathrm{RFO})$ than chloroform fractions $(77.55 \pm 6.87 \mathrm{mg} \mathrm{KOH} / \mathrm{g}$ RFO). Therefore, hexane fraction is subjected to lower hydrolytic and lipolytic degradation than that of chloroform fraction. Saponification value is used to estimate the molecular weight of fatty acids in RFO. The saponification value of RFO in chloroform fraction $(155.01 \pm 0.52 \mathrm{mg} \mathrm{KOH} / \mathrm{g}$ RFO$)$ is higher than in hexane $(127.30 \pm 1.36 \mathrm{mg} \mathrm{KOH} / \mathrm{g} \mathrm{RFO})$. The iodine value indicates the unsaturation degree of fats and oils. The higher level of iodine value, the more unsaturated fatty acids in RFO. RFO contains more unsaturated fatty acid in hexane fraction $\left(81.48 \pm 4.59 \mathrm{gI}_{2} / 100 \mathrm{~g} \mathrm{RFO}\right)$ than in chloroform fraction $\left(70.73 \pm 3.38 \mathrm{~g} \mathrm{I}_{2} / 100 \mathrm{~g} \mathrm{RFO}\right)$.

The conjugated diene (CDs) and triene (CTs) values at 232 and $270 \mathrm{~nm}$, respectively in the UV spectrum is related to the formation of peroxides (Wanasundara et al., 1995). The content of CDs and CTs can serve as a relative measurement of oxidation (Pegg, 2005). The CDs value of RFO in hexane fractions $(3.03 \pm 0.07 \mathrm{~g} / 100$ $\mathrm{mL} \mathrm{cm}{ }^{-1}$ ) is not statistically different with $\mathrm{CDs}$ value from chloroform fractions $(3.02 \pm 0.008 \mathrm{~g} / 100 \mathrm{~mL} \mathrm{~cm}$ $\left.{ }^{1}\right)$. However, the CTs value of RFO in chloroform fraction $\left(2.56 \mathrm{~g} / 100 \mathrm{~mL} \cdot \mathrm{cm}^{-1}\right)$ was higher than in hexane fraction $\left(1.68 \mathrm{~g} / 100 \mathrm{~mL} . \mathrm{cm}^{-1}\right)$ (Arumsari et al., 2013). Anisidine values measure the formation of 2-alkenals which is used to measure the extent of secondary oxidation products in fats and oils (Laguerre et al., 2007). Anisidine values of RFO in hexane fraction (21.37) was higher than that of RFO in chloroform fraction (19.46).

Fatty acids are an essential components of edible fats and oils. The quantitative analysis of fatty acids is important in fats and oils because fatty acid composition can be used as characteristics property and nutritional information of edible fats and oils (Carrosco-Pancorbo et al., 2009). Rohman et al. (2012) have measured the fatty acids compositions of RFO, as determined using gas chromatography with flame ionization detector. Table 1 detailed fatty acid composition of RFO. The main fatty acids composed of RFO were oleic acid (C18:1) and linoleic $(\mathrm{C} 18: 2)$ acids with the concentration of $68.80 \%$ and $8.49 \%$, respectively. It is believed that the high presence of monounsaturated fatty acid (oleic acid) in RFO can contribute to the beneficial effects to human health (Fomuso and Akoh, 2002).

Table 1. Fatty acid composition of red fruit oil (Rohman et al., 2012).

\begin{tabular}{cc}
\hline Fatty acid & Concentration (\%) \\
\hline C12:0 & $0.06 \pm 0.02$ \\
C14:0 & $0.07 \pm 0.00$ \\
C14:1 & $0.15 \pm 0.00$ \\
C16:0 & $20.05 \pm 0.09$ \\
C16:1 & $0.15 \pm 0.01$ \\
C18:0 & $0.18 \pm 0.01$ \\
C18:1 & $68.80 \pm 1.29$ \\
C18:2 & $8.49 \pm 0.02$ \\
C18:3n6 & $0.17 \pm 0.00$ \\
C20:0 & $0.13 \pm 0.00$ \\
\hline
\end{tabular}

The volatile compounds of RFO also have been evaluated by Rohman et al. (2012) using gas chromatography-mass spectrometry using headspace analyzer (GC-MS-HS). There are 35 volatile compounds identified with the main components are 1,3-dimethylbenzene $(27.46 \%)$, N-glycyl- L-alanine (17.36\%), trichloromethane (15.2\%), and ethane (11.43\%).

\section{The biological activities of RFO}

RFO has been known as a natural food supplement containing medicinal qualities and as a dye. RFO can be considered as functional food oils due to its ability to give several biological activities (Rohman and Che Man, 2012). Several studies have been reported on the biological activities of RFO. RFO has an effect on anticancer activity. Local communities in Indonesia believed that RFO can treat several degenerative diseases such as cancer, arteriosclerosis, rheumatoid arthritis, and stroke (Budi and Paimin, 2004) as well as HIV, malaria, cholesterol, and diabetes mellitus (Limbongan and Malik, 2009).

RFO was found to inhibit the growth of lung cancer cell A549 at doses of $500 \mathrm{mg}$ of fruit extract $/ \mathrm{mL}$ dissolved in dimethylsulfoxide (DMSO). The presence of $\beta$-cryptoxanthin could cause the growth inhibition of lung cancer cells associated with smoking (Lim, 2013). Another study showed that RFO exhibited antitumour effects in either tumour volumes or tumour weights against mouse Sarcoma-180, Lewis lung cancer and human nonsmall lung cancer A549 bearing mice (Lim, 2013). Animal studies showed that RFO could reduce the serum level of proinflammatory cytokines, such as TNF- $\alpha$ (tumour necrosis factor- $\alpha$ ), IFN- $\gamma$ (interferon- $\gamma$ ) and IL-1 (interleukin-1) in experimental colorectal cancer model mice (Oeji and Khiong, 2010). RFO with different concentrations has been reported to significantly decrease the rate of reactive oxygen 
intermediate (ROI) production of endothelial cells. RFO can neutralize oxidative stress of cells by reducing ROI production of endothelial cells exposed to severe malaria patient serum and neutrophils from healthy donor in vitro (Armiyanti et al., 2007).

Another study reported that RFO has a hypoglycaemic activity. A combination of RFO and glibenclamide produced a significant reduction in blood glucose in diabetic-treated rats. The results showed that RFO could increase the hypoglycaemic effect of glibenclamide on diabetic rats (Winarto et al., 2009). RFO at dose of $0.9 \mathrm{~mL} / \mathrm{kg}$ b.w. significantly inhibited inflammation in female wistar rats after carrageen induced inflammation with inhibition rates of 72.5, 69.2, and $85 \%$ at 3,4 , and 24 hours respectively, compared to control rats (Sukandar et al., 2005). With its high presence of monounsaturated fatty acid (oleic acid), RFO is believed to have beneficial effects for human health such as preventing cardiovascular diseases, reducing plasma triacylglycerol (TAG), increasing high density lipoprotein (HDL)-cholesterol levels, improving the postprandial lipoprotein metabolism, reducing blood pressure and the risk of hypertension, having anticancerogenic effects in animal models and in human cell lines, not promoting obesity and increasing the lipolytic activity in adipose tissue, and preventing age-related cognitive decline and dementia (García-González et al., 2008).

\section{Authentication of RFO}

Due to the high-priced value of RFO in the Indonesian fats and oils market, some unethical players try to blend RFO with other vegetable oils having low price value such as palm oil and corn oil. This is based on fact that the economic profit obtained from fats and oils industry is relatively narrow, compared to pharmaceutical industry (Asensio et al., 2008; Schieber, 2008; Arlorio et al., 2010). Authentication analysis of RFO becomes important in order to ensure the quality of RFO from adulteration practices. Some analytical methods have been developed, and the most reported are Fourier transform infrared (FTIR) spectroscopy. Due to its property as fingerprint technique, FTIR spectroscopy is widely used for the authentication of RFO. FTIR spectroscopy in combination with chemometrics of multivariate calibration and classification technique such as principal component analysis (PCA) and discriminant analysis (DA) becomes a powerful method for authentication purposes (Rohman, 2012; Rohman and Che Man, 2012).

The authentication of RFO from corn oil (CO) is performed by spectroscopy FTIR combined with chemometrics of multivariate calibration of partial least square (PLS). Some wavenumbers regions were optimized to analyze $\mathrm{CO}$ in RFO. The combined wavenumbers y region of $1600-1800 \mathrm{~cm}^{-1}$ and $800-1200$ $\mathrm{cm}^{-1}$ were selected for quantification of $\mathrm{CO}$ in RFO. During PLS calibration models, these wavenumbers regions showed the lowest values of root mean error of calibration (RMSEC) and root mean square error of prediction (RMSEP) and the highest values of coefficient of determination $\left(\mathrm{R}^{2}\right)$ using FTIR normal spectra. The RMSEC and $\mathrm{R}^{2}$ values obtained are $0.987 \%$ and 0.998 , respectively. In order to validate the developed model, some independent samples comprising the mixture of $\mathrm{CO}$ and RFO are measured using the same condition used for determining calibration samples. The RMSEP value of $\mathrm{CO}$ in RFO obtained was $1.195 \%$ (Setyaningrum et al., 2013). The high value of $\mathrm{R}^{2}$ and low values of RMSEC and RMSEP obtained indicated that the developed PLS calibration model exhibited acceptable accuracy and precision, therefore, the developed model can be used for authentication of RFO from $\mathrm{CO}$.

Rohman et al. (2011) have developed the model for authentication of RFO from canola oil $(\mathrm{CaO})$ using FTIR spectroscopy in combined with multivariate calibration of partial least square. Using the optimization process, the frequency region of $1200-1050 \mathrm{~cm}^{-1}$ was used for quantification of $\mathrm{CaO}$ due to the high correlation between actual value and FTIR measured values of $\mathrm{CaO}$ in RFO. The coefficient of determination $\left(\mathrm{R}^{2}\right)$ value obtained was 0.999 . The error during calibration as expressed as root mean square error of calibration (RMSEC) was $0.812 \%(\mathrm{v} / \mathrm{v})$. The PLS model was further used to predict the level of $\mathrm{CaO}$ using laboratory prepared samples. The $\mathrm{R}^{2}$ value for correlation between actual and measured values of $\mathrm{CaO}$ in prediction models is 0.996 with a root mean square error of prediction (RMSEP) of $1.05 \%(\mathrm{v} / \mathrm{v})$. In order to validate the performance of the PLS model, leave-one-out-technique was used. The root mean square error of cross validation (RMSECV) obtained was $2.28 \%$ with an $\mathrm{R}^{2}$ of 0.990 . Discriminant analysis (DA) is a chemometric technique with supervised pattern recognition type which allocates a new object of the unknown group to the correct group (Miller and Miller, 2005). DA using frequency regions of $1200-1050 \mathrm{~cm}^{-1}$ can discriminate pure RFO samples and those adulterated with $\mathrm{CaO}$ and $\mathrm{RBO}$ with no misclassification reported during the study (Rohman et al., 2011).

The authentication of RFO from soybean oil (SO) is performed using FTIR spectroscopy in combined with chemometrics multivariate calibrations. It can be shown that the normal spectra in combination with PLS calibration technique at two frequencies of 1600-1800 $\mathrm{cm}^{-1}$ and $800-1200 \mathrm{~cm}^{-1}$ is the better model, in terms of the highest $\mathrm{R}^{2}(0.997)$, the lowest values of RMSEC $(1.195 \% \mathrm{v} / \mathrm{v})$ for the relationship between the actual 
value and the predicted value. The validation/prediction model showed that the RMSEP value obtained was $1.063 \%(\mathrm{v} / \mathrm{v})$ (Setyaningrum et al., 2013).

The presence of rice bran oil (RBO) in RFO also has been exploited using FTIR spectroscopy in combined with partial least square. The two combined frequencies of two region ranges (1207-1078 and $\left.1747-1600 \mathrm{~cm}^{-1}\right)$ were selected for this analysis. The coefficient of determination $\left(\mathrm{R}^{2}\right)$ value obtained was 0.996 . The root mean square error of calibration (RMSEC) value obtained was $0.957 \% \mathrm{v} / \mathrm{v}$. The root mean square error of prediction (RMSEP) and the $\mathrm{R}^{2}$ value for prediction was 0.991. Using two principal components, the RMSECV value obtained was $1.91 \%$ (v/v) (Rohman et al., 2011).

FTIR spectroscopy coupled with multivariate calibration of PLS is also used for quantitative analysis of sunflower oil (SFO) and palm oil (PO) as oil adulterants in RFO for authentication purposes. Some wavenumbers are optimized to seek the best wavenumbers region, FTIR spectral treatment including derivatization and its combination capable of the best predicting of adulterant levels in RFO. Based on R2 and RMSEC values obtained, the wavenumber regions 1780 $1680 \mathrm{~cm}^{-1}$ using FTIR normal spectra was more preferred than its derivative for quantitative analysis of $\mathrm{PO}$ in RFO. The $\mathrm{R}^{2}$ and RMSEC values obtained are 0.9991 and $0.98 \% \mathrm{v} / \mathrm{v}$, respectively. FTIR normal spectra at $1200-1000 \mathrm{~cm}^{-1}$ was used for quantification of SFO in RFO with R2 and RMSEC value of 0.991 and $1.09 \% \mathrm{v} / \mathrm{v}$, respectively (Rohman et al., 2014).

\section{Conclusion}

RFO has been recognized as functional food oils because of its beneficial effects on human health. The high quality of RFO served as preventive agents of various diseases, therefore RFO has high price oils in the market. RFO is potential to be adulterated with other lower quality and lower price oils, therefore the authentication of RFO is very important. FTIR spectroscopy combined with chemometrics multivariate calibrations is a powerful method for the detection and quantification the adulteration practices in RFO.

\section{References}

Asensio, L., Gonzalez, I., Garcia, T. and Martin, R. (2008). Review: Determination of food authenticity by enzyme-linked immunosorbent assay (ELISA). Food Control, 19, 1-8. https://doi.org/10.1016/ j.foodcont.2007.02.010

Arlorio, M., Coisson, J.D., Bordiga, M., Travaglia, F., Garino, C., Zuidmeer, L., Van Ree, R., Giuffrida, M.G., Conti, A. and Martelli, A. (2010). Olive oil adulterated with hazelnut oils: Simulation to identify possible risks to allergic consumers. Food Additive and Contaminants, 27, 11-18. https:// doi.org/10.1080/02652030903225799

Armiyanti, Y.L., Fitri, L.E. and Widjajanto, E. (2007). The effect of red fruit oil (Pandanus conoideus) on oxidative stress of endothelial cells exposed to malaria falciparum patient serum and healthy donor neutrophil. Jurnal Kedokteran Brawijaya, 28, 1 -8.

Arumsari, N.I., Riyanto, S. and Rohman, A. (2013). Some physico-chemical properties of red fruit Oil (Pandanus conoideus Lam) from Hexane and Chloroform Fractions. Journal of Food and Pharmaceutical Sciences, 1, 30-34.

Bourke, R.M. (2005). Indigenous Fruit in Papua New Guinea. Report of Departement of Human Geography. Australia: The Australian University.

Budi, M. and Paimin, F.R. (2004). Red Fruits (Pandanus conoideus Lam.). Jakarta: Penebar Sawadaya.

Carrosco-Pancorbo, A., Navas-Iglesias, N. and CuadrosRodriguez, L. (2009). From lipid analysis towards lipidomics, a new challenge for the analytical chemistry of the $21^{\text {st }}$ century. Part I: Modern lipid analysis. Trends in Analytical Chemistry, 28, 263 277. https://doi.org/10.1016/j.trac.2008.12.005

Fomuso, L.B. and Akoh, C.C. (2002). Lipase-catalyzed acidolysis of olive oil and caprylic acid in a benchscale packed bed bioreactor. Food Research International, 35, 15-21. https://doi.org/10.1016/ S0963-9969(00)00158-7

Laguerre, M., Lecomte, J. and Villeneuve, P. (2007). Evaluation of the ability of antioxidants to counteract lipid oxidation: Existing methods, new trends and challenges. Progress in Lipid Research, 46, 244-282. https://doi.org/10.1016/j.plipres.2007.05.002

Lim, T.K. (2013). Pandanus conoideus. In Lim, T.K. (Ed). Edible Medicinal and Non-Medicinal Plants, p. 117-123. Germany: Springer.

Limbongan, J. and Malik, A. (2009). Opportunity of red fruit crop (Pandanus conoideus Lam.) development in Papua Province. Jurnal Penelitian dan Pengembangan Pertanian, 28(4), 134-141 (Bahasa Indonesia).

Miller, J.N. and Miller, J.C. (2005). Statistics and Chemometrics for Analytical Chemistry. $5^{\text {th }}$ ed. Harlow: Pearson Education.

Mousavi, K., Shoeibi, S. and Ameri, M. (2012). Effects of storage conditions and PET packaging on quality of edible oils in Iran. Advances in Environmental Biology, 6(2), 694-701.

Pegg, R. (2005). Lipid oxidation stability. In Wrolstad R.E. (Ed). Handbook of Food Analytical Chemistry: Water, Proteins, Enzymes, Lipids, and Carbohydrates, p. 513 - 547. Canada: John Wiley 
and Sons.

Rohman, A. (2012). Application of FTIR spectroscopy for quality control in pharmaceutical products: a review. Indonesian Journal of Pharmacy, 23(1), 1-8.

Rohman, A. and Che Man, Y.B. (2008). Analysis of lard in food products for halal authentication study. Agritech, 28(4), 192-201.

Rohman, A. and Che Man, Y.B. (2012). Application of Fourier Transform Infrared Spectroscopy for Authentication of Functional Food Oils. Applied Spectroscopy Review, 47(1), 1-13.

Rohman, A., Riyanto, S., Yuniarti, N., Saputra, W.R., Utami, R. and Mulatsih, W. (2010). Antioxidant activity, total phenolic, and total flavonoid of extracts and fractions of red fruit (Pandanus conoideus Lam). International Food Research Journal, 17, 97-106.

Rohman, A., Che Man, Y.B. and Riyanto, S. (2011). Authentication Analysis of Red Fruit (Pandanus conoideus Lam) oil using FTIR spectroscopy in combination with chemometrics. Phytochemical Analysis, 22(5), 462-467. https://doi.org/10.1002/ pca. 1304

Rohman, A., Riyanto, S. and Che Man, Y.B. (2012). Characterization of red fruit (Pandanus conoideus lam) oil. International Food Research Journal, 19 (2), 563-567.

Rohman, A., Riyanto, S., MartSasi, A. and Yusof, F.M. (2014). The use of FTIR spectroscopy in combination with chemometrics for the authentication of red fruit (Pandanus conoideus Lam) oil from sunflower and palm oils. Food Bioscience, 7, 64-70. https://doi.org/10.1016/ j.fbio.2014.05.007

Schieber, A. (2008). Introduction to Food Authentication. In Sun, D.W. (Ed). Modern Techniques for Food Authentication, p. 1-23. New York: Elsevier.

Setyaningrum, D.L., Riyanto, S. and Rohman, A. (2013). Analysis of corn and soybean oils in red fruit ois using FTIR spectroscopy in combination with partial least square. International Food Research Journal, 20(4), 1977-1981.

Sukandar, E.Y., Suwendar and Adnyana, I.K. (2005). Anti-inflammation activity of red fruit (Pandanus conoideus Lamk.) oil on Wistar female rats. Acta Pharmaceutica Indonesia, 30(3), 76-79.

Wanasundara, U.N., Shahidi, F. and Jablonski, C.R. (1995). Comparison of standard and NMR methodologies for assessment of oxidative stability of canola and soybean oils. Food Chemistry, 52, 249 -253. https://doi.org/10.1016/0308-8146(95)92819-6

Winarto, Madiyan, M. and Anisah, M. (2009). The effect of Pandanus conoideus Lam. Oil on pancreatic B- cells and glibenclamide hypoglycaemic effect of diabetic Wistar rats. Berkala Ilmu Kedokteran, 41(1), 11-19. 